\title{
A literatura das margens: análise da letra da canção "A vingança" como valorização do rap nos estudos literários contemporâneos
}

The literature from the margins: analysis of the lyrics of the song "A vingança" as an expression of rap in contemporary literary studies

\author{
Augusto Moretti de Barros ${ }^{1, a}$ (D), Rafaela Souza Maldonado ${ }^{2, b}$ (iD \\ ${ }^{1}$ Universidade Estadual Paulista, Brasil \\ ${ }^{2}$ Universidade Estadual Paulista, Brasil \\ a augusto.moretti@unesp.br b rafaela_maldonado@hotmail.com
}

Recibido: 14/10/2021; Aceptado: 21/11/2021

\section{Resumo}

Neste artigo, entendemos que a literatura das margens deve ocupar espaços de destaque nos trabalhos acadêmicos, pois é uma manifestação literária que representa perspectivas sobre temas importantes, como a discriminação e a violência, a partir de autores que vivenciam tais contextos e através de um trabalho linguístico que compõe de maneira muito significativa e particular as obras. Sob este viés, defendemos o trabalho com as letras de canções, mais especificamente de rap, para dar voz a esta literatura marginalizada, que apresenta características que a colocam no mesmo nível que as obras já consagradas. Para nossa investigação, selecionamos o rap "A vingança", de 1998, composto e interpretado pelo grupo paulista Face da Morte. Em nossas análises, apresentamos como principais escolhas teóricas: Benjamin (1994) para tratar da construção narrativa; Pellegrini (2005) e Hollanda (2018) como fonte para abordar a temática da exclusão e da violência na literatura contemporânea; e Barthes (2000) como base para entender as escolhas linguísticas feitas pelo narrador. Assim, buscamos destacar de que maneira a letra do rap aborda a violência e constrói seus personagens dentro dessa temática.

Palabras chave: literatura contemporânea; literatura marginal; violência; letra de rap; "A vingança”.

\begin{abstract}
In this article we understand that the margin literature must occupy prominent space in academic studies, as it is a literary expression that represents important themes, such as discrimination and violence, from authors who experience such environment and through a linguistic performance that makes up the work in a very significant and particular way. In this regard, we support the work with songs lyrics, more specifically rap music, so that it can give voice to this marginalized literature which presents characteristics that place it on the same level as the works that have already been established. For our investigation, we selected the rap song "A vingança", from 1998, composed and performed by the group from São Paulo, Face da Morte. In our analysis we present as main theoretical framework: Benjamin (1994) to deal with the narrative
\end{abstract}


construction; Pellegrini (2005) and Hollanda (2018) as a source to address the theme of exclusion and violence in contemporary literature; and Barthes (2000) as a basis for understanding the linguistic choices made by the narrator. Thus, we aim to highlight how the rap lyrics approach violence and develop its characters within this theme.

Keywords: contemporary literature; marginal literature; violence; rap lyrics; "A vingança".

\section{CONSIDERAÇÕES INICIAIS}

A violência urbana vivida pela população marginalizada é refletida na arte, de modo que é representada pelos sujeitos que vivem sob aquela realidade por meio de diferentes manifestações. Na literatura brasileira, são vários os exemplos de autores que abordam a temática da violência em suas obras (Amado, 1937; Ramos, 1953; Melo Neto, 1955), o que oferece uma porta de entrada, inclusive, para a voz de um povo que vive nas margens da sociedade. A expressão das periferias na literatura ganhou força, principalmente, a partir do século XX com o movimento modernista e seus desdobramentos com a geração de 1970 e a chamada literatura marginal, que na época propunha novos contextos de circulação para o texto literário, adotando novas temáticas, estruturas e conquistando novos públicos. Em entrevista ao site Margens, Heloísa Buarque de Hollanda, pesquisadora sobre literatura marginal, conta como se deu a divulgação do movimento setentista:

A [literatura] marginal dos anos 70 é uma coisa visceralmente ligada à contracultura. 0 projeto da contracultura "pular fora" do sistema e propor alternativas. Era uma literatura marginal ao sistema editorial, ao cânone literário, mas não era marginal a sociedade. Eram todos brancos, de classe média, universitários. A diferença grave é essa. Esse tipo de literatura marginal ganhou muita repercussão, conquistou pessoas que não gostavam de poesia e que passaram a gostar por conta da poesia marginal, como a gente vê hoje. Isso porque [nos anos 70] se aliou ao rock n'roll, então os shows de poesia marginal tinham também uma banda de rock tocando, alternando. (Hollanda, 2018)

Na mesma entrevista, a estudiosa atualiza sua visão sobre o tema, ao lembrar que o poeta marginal setentista não tem o mesmo perfil do artista da atualidade, pois "o marginal de hoje é um excluído da sociedade. Mas os dois marginais funcionaram muito no sentido de recolocar a questão da validação da poesia" (Hollanda, 2018). A partir dessa premissa, consideramos que a literatura marginal ainda não era totalmente inclusiva, mas foi importante para que outras culturas pudessem se manifestar. Além disso, vemos o perfil do artista mudar ao longo do tempo, passando do modelo observador científico do realismo, para aquele que vivencia a própria mazela.

No Brasil, alguns nomes que representam a produção dentro dessa temática em prosa são Marçal Aquino, Dalton Trevisan, Marcelino Freire e Ferréz; na poesia, podemos destacar Paulo Leminski, Ana Cristina César, Sérgio Vaz e Luiza Romão. Elencamos tais autores para reconhecer a importância da abertura do campo literário para a escrita que se aproxima do real, tanto no que diz respeito ao tema, quanto no trabalho com a língua. Além disso, é necessário observar que esses autores trabalhavam no sentido contrário ao da academia, mesmo pertencendo a uma elite social. No caso dos rappers, a legitimação de seu trabalho a um status de arte se deu a passos lentos, mas se orgulha de pertencer ao cenário periférico e poder representá-lo.

Consideramos, com base em Fischer (2014), que a canção é um gênero de escrita em verso que pode ser compreendido, interpretado e analisado como literário, sobretudo por suas semelhanças 
com outros tipos de textos que nasceram distantes do cânone, como o teatro e a crônica, porém conquistaram o status de literatura. Segundo o autor, o conceito de literatura

[...] engloba canção, gênero semiliterário, semimusical, cujo estatuto particular, de todo modo, mais o inclui no repertório letrado do que o exclui dele. A canção pertence ao mundo literário tanto quanto o teatro, ao menos. São, os dois, gêneros claramente letrados, cuja seiva depende da palavra, sendo nisso aparentados diretos dos gêneros tradicionais do domínio literário (e os dois, por certo, vivem também outras realidades, relativas ao mundo da performance e da música). Creio que ocorrerá, a médio prazo, com a canção, aquilo que ocorreu com a crônica, que foi admitida no campo literário apenas nos anos 1970, após décadas de vida fértil no jornal e na formação do brasileiro real. (Fischer, 2014, p. 574)

Uma vez que aproximamos a canção dos gêneros já consagrados pela literatura, é importante destacar que, entre eles, o que mais possui características comuns a conceitos musicais é o gênero lírico, pois a poesia é composta, de maneira geral, por versos, estrofes e recursos sonoros, tais como rima, ritmo e figuras de linguagem fonolexicais. Esses aspectos, que podem ser encontrados na poesia, nos permitem traçar um paralelo com as estruturas linguísticas que formam as letras de canções.

Destacamos que, embora a canção se aproxime do gênero lírico em relação aos aspectos formais elencados, ela possui uma característica que a difere da poesia tradicional: a construção de uma narração. No caso do rap, principalmente, é comum que haja uma narrativa e, consequentemente, os elementos próprios do gênero: narrador, enredo, tempo, espaço e personagens. Assim, a letra de canção é um gênero literário que está nessa intersecção entre o lírico e o narrativo.

Dentre os estilos musicais, existem aqueles que têm maior comprometimento, em suas letras, com a oportunidade de dar voz para quem não ocupa espaços sociais de privilégio: no Brasil, podemos citar o samba, o funk e o rap. No caso do rap, vemos como a periferia aborda seu cotidiano e expõe suas vivências. São sujeitos que foram invisibilizados pela sociedade e pelas autoridades e que, por meio da arte, conseguem tomar voz e expor o seu cotidiano, sua história e sua memória, ressignificando e valorizando a cultura local.

Desse modo, analisamos, neste artigo, a forma com que a violência afeta a população marginalizada que vive em periferias e de que modo o tema se reflete nas suas escolhas e modo de vida, além de analisar a inserção dessa temática na literatura, valorizando a manifestação da cultura e da arte periféricas. Também neste artigo, descrevemos a forma com que essa violência é apropriada na construção de uma narrativa e de seus personagens.

Nosso objeto de investigação é a letra da canção "A vingança", do grupo paulista de rap Face da Morte. Embora tenha conquistado certo espaço e reconhecimento no cenário do rap, sobretudo nos anos 1990, o grupo não alcançou grande repercussão e há pouco material documentado sobre ele. Seus fundadores e vocalistas são: Aliado G e Mano Ed, que também são os compositores das músicas e já revelaram, ao serem entrevistados pelo site Submundo do som, em 2018, que se baseiam na realidade que os rodeia para escrever as letras. Dessa maneira, o rap se localiza na literatura que aborda o real, que o ficcionaliza e atribui sobre ele a ótica artística, o que nos permite aferir que pertence, ainda, ao movimento literário que busca deixar as margens e chegar ao centro.

A canção analisada neste artigo foi lançada no segundo álbum do grupo, intitulado Quadrilha de morte, de 1998, localizado temporalmente em uma década que foi muito significativa para o rap nacional. Nesse período, o ritmo tem seu auge, no Brasil, com a divulgação de importantes nomes como Racionais MC's, Realidade Cruel, Pavilhão 9, Detentos do Rap, Planet Hemp e Gabriel, 0 Pensador, todos trabalhando com a rima para alertar sobre a realidade das comunidades brasileiras, o preconceito da sociedade, os abusos dos ricos em relação aos pobres e denunciando o descaso 
das autoridades. Apesar disso, na fase inicial do rap no país, as estruturas sociais ainda eram menos abertas para que ele alcançasse o status de arte, cenário que segue em ascensão, dentre outros motivos, por conta do olhar que a mídia volta para o gênero e relativa facilidade de divulgação e reprodução em mídias digitais que temos hoje em dia.

Assim como o reggae, o rap surgiu na Jamaica, na década de 1960, e foi incorporado à cultura norte-americana. A sigla rap (formada a partir dos termos "ritmo e poesia" em língua inglesa) faz parte da cultura do hip-hop, incorporada à cultura brasileira na década de 1970, importada dos Estados Unidos. Segundo Miranda (2010), a cultura em questão foi ressignificada ao chegar no Brasil, de modo que, nos anos de 1980, passou a representar o estilo de vida da população jovem das periferias brasileiras. Assim, de acordo com a autora, o movimento do hip-hop abarca uma série de modalidades artísticas como a música ( $r a p)$, a dança (break), a arte gráfica (graffiti), bem como seus atores sociais que são orapper ou $M C$ (mestre de cerimônia), conhecidos por serem os cantores, compositores e até repentistas; o b-boy, dançarino; e o $D J$ que faz os arranjos das músicas para os rappers.

As letras do estilo musical, geralmente, possuem a temática de protesto, tendo como mote as experiências vividas pelos seus autores, isso por que, ainda segundo Miranda:

Tanto no rap quanto na literatura marginal temas como a violência (com destaque para uma oposição à violência policial), o preconceito e as desigualdades econômica e social são muito frequentes e as respectivas performances revelam uma postura política e ideológica que insere o sujeito da enunciação em uma posição de agente social, que vê a palavra como instrumento de mudança, embora esta modificação não possa ser vista como uma ruptura com o sistema dominante. (Miranda, 2010, p. 6)

Em certa medida, a voz do rapper e toda a cultura hip-hop se consolida como forma de resistência, no sentido de se opor ao sistema vigente, pois se constrói diante de um contexto de desigualdade, divulgando valores, denunciando realidades e agindo sobre seus ouvintes, mostrando que essa manifestação artística serve como instrumento de mudança, como mencionou Miranda (2010). Isto é, embora o rap tenha, ao longo dos anos, alcançado reconhecimento e visibilidade, ele é um discurso localizado, que exprime a ideologia de determinada parcela da sociedade que tenta impor sua existência em uma sociedade que a oprime.

Apesar das dificuldades de se estabelecer no cenário artístico, conseguimos ver a influência dos rappers do passado nos intérpretes dos dias atuais, bem como a conquista de um espaço acadêmico para o gênero. Podemos percebê-lo por meio dos estudos de Miranda (2010), dos projetos de Heloísa Buarque de Hollanda -em entrevista ao site Margens, Hollanda discorre sobre o projeto que coordena, o "Universo das Quebradas", cujo objetivo é estabelecer um diálogo entre a academia e as periferias e criar um terceiro produto (Hollanda, 2018)- e deste artigo.

É interessante destacar que a canção que analisamos inclui os dois ritmos originariamente jamaicanos, pois a música conta com um sample da canção "Não chores mais", versão brasileira, interpretada por Gilberto Gil, da música "No woman, no cry”, de Bob Marley. Na época, era comum os cantores de rap utilizarem amostras de outras músicas como refrões em suas letras. Desse modo, o efeito alcançado era de quebra da intensidade tanto da batida, quanto da letra. Na canção "A vingança", além de apontar para uma musicalidade diferente, o sample ainda tem a função de ilustrar o estado de espírito da personagem feminina, que se degrada ao longo da narrativa, depois de ter sido abusada pelo filho de seu patrão, como veremos em sua análise ao longo deste artigo.

A partir do exposto, ressaltamos a importância de analisar a letra da canção "A vingança" a partir da teoria literária, com base em Pellegrini (2005) e em Hollanda (2018), que esclarecem a temática 
da violência e da exclusão social no âmbito da literatura contemporânea; em Benjamin (1994), que nos respalda em relação à construção narrativa; e em Barthes (2000), que nos dá a base necessária para investigar as escolhas linguísticas feitas pelo narrador. Assim, buscamos salientar a maneira com que a letra do rap aborda a violência e constrói seus personagens dentro dessa temática, e estruturamos nossas análises em seções que seguem os estudos dos autores elencados.

\section{TRAJETÓRIAS QUE REVELAM A FACE DA VIOLÊNCIA NA CANÇÃO “A VINGANÇA"}

\subsection{A violência que permeia a narrativa}

A canção "A vingança" narra a trajetória de três personagens: Maria, uma retirante que trabalha como empregada doméstica em uma casa de família e é abusada sexualmente pelo filho de seu patrão, quando ainda tinha treze anos; o filho, resultado dessa violência sexual; e o abusador, que também é um importante personagem, pois tem a sua jornada cruzada com a dos protagonistas. 0 narrador é onisciente e demonstra condescendência pela mãe e pelo filho, principalmente ao narrar o contexto em que eles desenvolvem suas ações e a caracterização desses personagens.

A narrativa é dividida em três momentos, com saltos temporais significativos para o seu andamento, entrecortados por um refrão, o sampleda canção "Não chores mais". A primeira parte nos apresenta Maria, seu patrão e o filho, fruto da violência sexual; na segunda parte, o filho vai dos sete aos doze anos de idade e a mãe está vivendo uma juventude relativamente tardia; e na terceira e última, o garoto já é adolescente e reencontra o homem que abusou de sua mãe. Com essa divisão, o narrador acompanha a trajetória de mãe e filho, destacando os principais elementos que culminam no desenlace anunciado desde o título.

Uma vez que compreendemos que a canção pertence à literatura, a letra do rap "A vingança" se insere nesse contexto de dar voz a quem é marginalizado, ressaltando com certa crueza a violência na sociedade. Para Tânia Pellegrini (2005), "Esse novo realismo caracteriza-se acima de tudo pela descrição da violência entre bandidos, delinqüentes, policiais corruptos, mendigos, prostitutas, todos habitantes do 'baixo mundo'” (p. 137). 0 novo realismo descrito por Pellegrini pode ser compreendido como a construção narrativa despida de pudores na forma e no conteúdo, é a linguagem visceral que trata de assuntos antes relegados ao esquecimento. É nesse contexto que o grupo de rap Face da Morte constrói a narrativa de sua canção.

\subsection{O olhar que define os sujeitos violentados}

Assim como a canção e a narrativa são compostas por três blocos, esse também é o número de personagens retratados ao longo da letra. A protagonista Maria deixa sua terra em busca de oportunidades na vida e encontra trabalho como empregada doméstica quando tinha apenas treze anos. Ao ser abusada sexualmente, ficar grávida e ser expulsa da casa em que trabalhava, vai morar em uma favela, lugar que representa o acolhimento para aqueles que precisam de um lar, sem distinção de cor, origem e sem julgamentos. Lá, ela tenta reconstruir a vida e criar o seu filho. 
Longe de buscar uma imagem romantizada do espaço que já é marginalizado socialmente, a canção também retrata as possibilidades que são oferecidas a quem não tem oportunidade na favela: o consumo e o tráfico de drogas. Maria, que é mãe muito jovem e perde a juventude por ter que trabalhar desde cedo e criar um filho com pouca diferença de idade, acaba se viciando em uma droga à base da mistura de maconha com crack, conhecida popularmente como "o famoso mesclado" (Face da Morte, 2018). Já seu filho entra cedo para a vida do crime, avançando em uma escala dentro desse universo.

Para discutir sobre a reverberação da violência expressa no texto, trazemos à luz a discussão de Walter Benjamin, quando o crítico literário afirma que "articular historicamente o passado não significa conhecê-lo 'como ele de fato foi'. Significa apropriar-se de uma reminiscência, tal como ela relampeja no momento de um perigo” (Benjamin, 1994, p. 224). Ou seja, a memória é a identificação de uma reminiscência no momento em que ela vem à tona. Ainda, nessas lembranças repercutem vozes oprimidas.

De fato, uma das questões que motiva a violência manifestada na vingança da personagem são os aspectos relacionados ao seu histórico, tanto de sujeito socialmente oprimido, quanto de abandono parental, que desencadeiam atitudes reativas, tal qual os relâmpagos aludidos por Benjamin. Além disso, o relato presente na narrativa é compartilhado por diversos atores sociais que vivem sob o mesmo contexto da narrativa, dando à reminiscência um caráter coletivo.

Assim, podemos considerar, à luz da teoria benjaminiana, o caráter realista da obra em questão, que foi construída a partir de um contexto de opressão e com uma linguagem escolhida para impor suas raízes, formas de pensamento e sua cultura musical. Esse viés analítico reforça a perspectiva de que a canção "A vingança" pode ser considerada como manifestação do novo realismo considerado por Pellegrini (2005).

Além do que foi abordado, há, na canção analisada, indícios do que podemos chamar de violência sistêmica, que é instaurada na sociedade e reproduzida de maneira bastante natural, mas que provoca impacto na formação humana, moral e ética do sujeito. Cremos que essa violência é gerada, entre outras coisas, pelo descaso das autoridades, o que leva o personagem da narrativa, morador de uma favela e com seu histórico de oprimido, a ter apenas as referências do que vivencia naquele ambiente. Sob essa perspectiva, observamos a necessidade de o sujeito recorrer a atitudes extremas como uma forma de reação à ameaça de violência direta ou outras formas de exploração, como prevê Žižek (2014) quando define a violência caracterizada como sendo inerente a um sistema em que não há necessariamente uma violência direta, mas sim relações de dominação e repressão.

Essa premissa se configura, na narrativa, no momento em que o narrador aborda a brincadeira com a qual o personagem estava acostumado: polícia e ladrão. De maneira bastante natural, o próprio narrador lança a questão aos ouvintes: "Agora tente adivinhar de que lado está" (Face da Morte, 1998) e finaliza a ideia desse verso, no seguinte: "Lá na favela não existe empresário pra ele se espelhar" (Face da Morte, 1998). A partir de então, vemos uma análise da violência sistematizada no ambiente em que o personagem vive, feita pelo próprio narrador. Além disso, no decorrer da narrativa o personagem conquista espaço no crime pelo seu bom desempenho desde a sua entrada nele, o que lhe garante status de respeito da sociedade local, o que vai de encontro ao seu histórico de rejeição que teve na infância. Maria, por sua vez, reage à violência sofrida ao longo de sua vida de maneira silenciosa, se rendendo ao uso de drogas.

Segundo Barthes (2000), todo falante de um idioma precisa fazer escolhas linguísticas, dentro do sistema em que está inserido, para se comunicar. Esse ato de seleção não é, para ele, uma necessidade, mas uma obrigação imposta pelo próprio sistema linguístico, o que caracteriza o 
fascismo que a língua exerce. Para o crítico francês, "Assim que ela é proferida, mesmo na intimidade mais profunda do sujeito, a língua entra a serviço de um poder" (Barthes, 2000, p. 7). Dessa maneira, a língua nos obriga sempre a dizer e cabe a nós escolhermos o que dizer e como dizer, revelando nossa subjetividade. Nessa perspectiva, as escolhas não são inocentes, mas sim dotadas de sentido e representam a visão que o autor tem sobre o assunto em questão. Assim, em um gênero curto como a canção, essas escolhas recebem uma atenção ainda maior, visto que as palavras são selecionadas não apenas para caber no ritmo, mas também, e principalmente, para dizer o que se quer dizer.

Uma vez que a canção possui um narrador que é onisciente, mas que demonstra juízos de valor, e que é por ele que conhecemos todos os personagens, organizamos, na Tabela 1, as escolhas lexicais feitas por ele para construir cada um. A seleção linguística feita pelo narrador revela, segundo a teoria barthesiana, seu posicionamento diante desses sujeitos:

Tabela 1. Características atribuídas aos personagens pelo narrador da canção "A vingança” em sua letra

\begin{tabular}{|c|c|c|c|}
\hline & Maria & $\begin{array}{l}\text { Filho do patrão de } \\
\text { Maria }\end{array}$ & Filho de Maria \\
\hline $1^{\mathrm{a}}$ parte da canção & $\begin{array}{l}\text { empregada; } \\
\text { um tesouro; } \\
\text { uma virgem; } \\
\text { um tremendo } \\
\text { mulherão; } \\
\text { isca fácil; } \\
\text { presa fácil; } \\
\text { inocente. }\end{array}$ & $\begin{array}{l}\text { um playboy } \\
\text { folgado; } \\
\text { fulano. }\end{array}$ & consequência. \\
\hline $2^{\mathrm{a}}$ parte da canção & $\begin{array}{l}\text { ausente; } \\
\text { dependente do } \\
\text { famoso mesclado; } \\
\text { bem louca. }\end{array}$ & $\begin{array}{l}\text { o personagem é } \\
\text { ausente nesta parte } \\
\text { da canção. }\end{array}$ & $\begin{array}{l}\text { moleque; } \\
\text { avião; } \\
\text { sangue bom; } \\
\text { mano. }\end{array}$ \\
\hline $3^{\mathrm{a}}$ parte da canção & $\begin{array}{l}\text { nesta parte da } \\
\text { canção, a mãe está } \\
\text { presente e as } \\
\text { informações sobre } \\
\text { ela são relacionadas } \\
\text { à trajetória do filho, } \\
\text { porém a } \\
\text { personagem não é } \\
\text { caracterizada. }\end{array}$ & $\begin{array}{l}\text { engravatado; } \\
\text { covarde. }\end{array}$ & $\begin{array}{l}\text { respeitado no } \\
\text { crime; } \\
\text { mano. }\end{array}$ \\
\hline
\end{tabular}

Em síntese, de acordo com Barthes, o falante escolhe, dentro do sistema linguístico em que está inserido, os recursos que melhor representam o que ele deseja comunicar ou expressar. 0 narrador, em posição de falante de um idioma, o faz de maneira a revelar a sua perspectiva diante da trajetória desses personagens, visando, em todo o texto, amarrar as pontas dessas três vidas, marcadas por eventos tão violentos.

Dessa maneira, podemos observar as seleções lexicais feitas pelo narrador para caracterizar cada um dos personagens. Para Maria, os atributos são sempre positivos, o que constrói uma imagem pura, porém sexualizada; já para o filho do patrão de Maria, são usados adjetivos pejorativos, demonstrando uma crítica a um perfil prototípico de um sujeito que possui uma posição alta dentro 
do sistema capitalista; e para o filho de Maria, as características escolhidas formam uma crescente no contexto criminal, porém, a partir de uma perspectiva que justifica esse caminho.

Maria é a única que tem nome próprio e que, embora seja um dos mais comuns atribuídos às mulheres brasileiras, a individualiza. Podemos inferir também que o nome, aliado ao fato de que ela era virgem até o momento em que foi violentada, remete ao personagem bíblico, Maria, que, segundo a crença católica, foi escolhida por Deus para gerar o seu filho, Jesus. Em contrapartida, a empregada doméstica retratada no rap concebe uma criança fruto de uma relação sexual marcada pela violência, pelo abuso de poder e pela opressão de classe social, e o menino sem nome cresce alimentando o ódio pelo homem que usou sua mãe.

Outra característica que o filho de Maria compartilha com Jesus é o fato de que ambos, ao serem concebidos, passam a viver uma espécie de sina, trilhando suas trajetórias em função de seus pais. Enquanto o personagem bíblico é gerado a partir do desejo de Deus de enviar seu filho à Terra para que ele cumpra a missão de levar a sua palavra de bondade para os seus contemporâneos, o jovem da canção é fruto de uma relação de violência, que resulta, além de na sua existência, na degradação de sua mãe, o que o faz crescer com ódio do pai. Dessa forma, Jesus cumpre o seu objetivo após pregar a palavra divina e, como consequência, sobe ao céu; já o filho de Maria encerra o seu propósito ao matar o homem que abusou de sua mãe e sentir-se vingado, decidindo dar um novo rumo ao seu futuro. No momento em que ele tira a vida daquele que lhe impôs a sua, ele se dá conta de que estar na criminalidade já não faz sentido, porque o ciclo de violência se fechou.

Nesse sentido, o sample da canção, além de contribuir para a quebra de ritmo da música e para pontuar de maneira clara o sequenciamento da narrativa, ainda dialoga diretamente com o contexto do rap, indicando, por meio das palavras "Não, não chores mais / Menina, não chore assim / Não, não chores mais / Procure a Deus, seu verdadeiro pai" (Face da Morte, 1998) que a figura divina era de fato a responsável por representar o papel paterno e não o homem que abusou de Maria. Logo, batizar a protagonista, única personagem que possui um nome próprio para individualizá-la, de maneira homônima à mãe do filho de Deus demonstra não ser uma escolha feita ao acaso, uma vez que se pode depreender a referência ao contexto bíblico a partir do sample.

Em suma, enquanto Maria tem suas qualidades ressaltadas pelo narrador, o que lhe atribui uma imagem benévola e vulnerável, o filho de seu patrão tem sua composição feita por palavras que demonstram a sua baixeza, mesmo pertencendo a uma classe social superior à de Maria e da qual ela é dependente. A canção põe em xeque conceitos como educação, valores e caráter, independente da camada social em que uma pessoa está inserida. 0 filho do patrão de Maria está acostumado a ter o que deseja, "só dá valor ao BMW que o pai lhe deu” (Face da Morte, 1998), isso o torna superficial, mesquinho e capaz de cometer um crime em nome de satisfazer seus ímpetos sexuais.

\subsection{A linguagem que revela trajetórias demarcadas}

O filho de Maria é o fio condutor da narrativa. É por meio de suas vivências, a partir da segunda parte da canção, que somos apresentados à realidade a que ele e sua mãe foram submetidos a viver, ainda acompanhamos as consequências do trauma causado em Maria e as suas dificuldades para lidar com a vida de mãe solteira. Para o narrador, o filho é um personagem de destaque, uma vez que ele se solidariza com a sua história, como no trecho "Parece um filme de terror, mas é a dura realidade / Talvez dura demais para um moleque dessa idade" (Face da Morte, 1998), o que indica juízos de valor atribuídos ao personagem. 
Assim, percebemos que a escolha do vocabulário influencia na forma de se colocar como sujeito na sociedade e que de certa forma enaltece os personagens em seu ambiente, mas o marginaliza em outro contexto; esse caso pode ser observado no tratamento que dá às transgressões das leis. No texto da canção, não encontramos recorrências à palavra "estupro", por exemplo, apenas construções linguísticas que dão a entender a forma com que o filho foi concebido.

Por outro lado, para tratar da ascensão pela qual o filho de Maria passa na vida criminal, não há constrangimento em enaltecer sua trajetória de evolução nos crimes que cometia, representados pelos números de artigos do Código Penal Brasileiro: 12 e 157 (crimes de tráfico de drogas e roubo, respectivamente), bem como a forma com que esses delitos são caracterizados e suas conquistas a partir deles. Isso se deve justamente à forma de reagir ao sistema e demonstrar resistência a ele: no ambiente em que vive isso demonstra status social e até mesmo a possibilidade de proteção a quem mora nas favelas. Além disso, apaga o fato de que um filho de um magnata tivesse cometido um crime, o que tornaria alguém que vem da favela mais perigoso do que aquele que mora nos condomínios dos grandes centros.

Quando Barthes (2000) nos mostra que a língua nos obriga a utilizar os recursos linguísticos disponíveis em nosso idioma para fins de expressão, inclusive a artística, o crítico francês nos chama também a atenção para as múltiplas formas de concretizar o que se quer dizer, deixando que o signo linguístico ganhe forma. Nessa perspectiva, destacamos que o narrador toma cuidado para não usar a palavra "pai" ao longo da canção, elegendo os contextos que demarcam a ausência da figura paterna para usá-la.

Nesse sentido, selecionamos o momento em que a palavra "pai" é utilizada na fala de um dos personagens, quando o filho de Maria comete um assalto no escritório do filho do ex-patrão de sua mãe. Este, então, ao se sentir totalmente vulnerável e dependente da misericórdia do garoto, apela aos seus sentimentos: "Pode levar o que quiser, mas não me mate / Eu sou seu pai". A palavra funciona como um gatilho para o jovem, que decide então matar aquele que mudou o destino de sua mãe, na tentativa de dar fim a esse enredo.

A condução da narrativa e, consequentemente, a trajetória do filho, flertam todo o tempo com a possibilidade muito próxima de haver um acerto de contas entre o jovem e o responsável pelo abuso contra a sua mãe. Desde o título, que é bastante revelador, encontramos na narração elementos que encaminham o enredo para o desfecho considerado como uma vingança: "O mundo gira e até as pedras podem se encontrar" (Face da Morte, 1998), verso presente na primeira da canção; "Mas tem um pressentimento que está perto o momento de sua vingança" (Face da Morte, 1998), trecho da terceira e última parte. 0 ouvinte/leitor vai, assim, criando uma expectativa para o encontro entre os dois personagens.

A partir da análise da canção apresentada, validamos a discussão sobre a utilização da linguagem como forma de representar o sujeito e sua forma de pensar individualmente e sua relação com o contexto em que está inserido. Por meio dessas perspectivas, foi possível perceber a forma com que temática, espaço e linguagem se relacionam dentro da canção, compondo um texto genuíno e conquistando valor artístico. Dessa maneira, alcançamos o objetivo primeiro deste artigo: valorizar e incluir a letra de rap nos estudos de literatura contemporânea. 


\section{CONSIDERAÇÕES FINAIS}

Visamos, neste artigo, descrever em que medida as teorias literárias se aplicam à análise da letra do rap "A vingança" do grupo Face da Morte. Benjamin (1994) e Barthes (2000) nos respaldam à medida em que destacamos a potência da linguagem escolhida pelo narrador para criar principalmente enredo, os personagens e a ambientação. Tal manejo linguístico não é inocente, ele revela o ímpeto de dar voz ao povo marginalizado, de inserir sua cultura musical no mercado e de representar os temas que lhe são caros.

Em consonância com outros estudos sobre letras de rap, como Malmaceda (2017), que dissertou sobre autores consagrados na literatura brasileira e suas aproximações com a obra musical do grupo Racionais MC's; Salgado (2015), que relacionou a literatura ao rap, entendendo este como palavra cantada; e Oliveira e Melo (2014), que abordaram as letras de rap como manifestações de protesto desveladas pela linguagem, buscamos, neste artigo, evidenciar tais aspectos literários, por meio da língua, na canção "A vingança".

A partir dos apontamentos sobre a literatura marginal e o rap, levando em consideração ainda o estudo de Miranda (2010), em que se faz uma ponte dialógica entre os dois movimentos, podemos observar os pontos em que eles se aproximam, tais como: seus projetos em relação à sociedade, os valores e realidades que eles pretendem divulgar e o interlocutor que ele pretende atingir, com a divergência de terem produtores artísticos diferenciados, pois no início pertencem a uma atmosfera intelectualizada e, posteriormente, abrangem novas esferas sociais.

Durante a análise do texto, permeado pela teoria, percebemos que a escolha de vocabulário é uma das formas escolhidas para reagir e se opor ao sistema, pois não coloca o personagem como marginal, mas como líder, pois está inserido nesse contexto quando demonstra naturalidade ao tratar de temas relacionados aos crimes que comete e as suas conquistas por conta de dele. A forma de resistência à violência sistêmica é a rendição à violência local, além disso, a busca por fama e dinheiro por meio do crime são formas de preencher o espaço paterno, como pode ser observado nas análises e que caem por terra depois de sua vingança.

Ainda no que se refere ao tema da violência, observamos uma reação em cadeia que nasce de maneira silenciosa, quando Maria é descartada do lugar onde trabalhava por ter engravidado, e esse trauma reflete em seu vício em drogas. Seu filho, que cresce diante de um contexto violento, mas que, de certa maneira, o protege, toma a posição de aderir ao sistema que o acolhe. E a partir desse momento, a violência começa a se tornar uma violência deliberada, em que o filho de Maria se torna respeitado pelo poder que adquire no crime.

Por suas características literárias, que possuem aproximações com o gênero lírico e com o gênero narrativo, podemos inferir que a letra do rap "A vingança” flerta com uma revisitação à epopeia, pois narra a trajetória de um herói/anti-herói -o filho de Maria-, a partir de uma narrativa em versos. Dessa maneira, apesar de não recorrer a elementos mitológicos, como é típico da epopeia, essa canção ressalta os feitos do filho de Maria como heroicos em um contexto de repressão social e de violência sistêmica.

Observamos, por meio da narrativa, as vozes periféricas localizadas tanto geograficamente quanto artisticamente. No âmbito geográfico, temos o papel social da favela: localizada nas periferias das grandes cidades e que acolhe todo tipo de morador, o que resulta na perspectiva apresentada neste artigo, como lugar inviabilizado pelas autoridades, além de possuir, no entanto, um estereótipo de espaço dominado pela violência por grande parte da sociedade brasileira. Já 
no âmbito artístico, o rap foi, desde o seu surgimento no Brasil, um ritmo marginalizado e que não ganhava espaço na área acadêmica, assim como a geração de 1970 e a poesia marginal até conquistar notoriedade nos estudos literários. Porém, a partir de alguns anos atrás, vemos esse cenário se modificar com a publicação de livros de poesia com letras das canções de rap, álbuns do gênero alcançando status de cânone e entrando para listas de vestibulares.

Concluímos que o rap tem ganhado certo espaço na academia e vem sendo reconhecido, ao longo dos anos, como manifestação literária, no entanto, ainda está longe de alcançar o reconhecimento equivalente à sua qualidade. Demonstramos, com a análise da letra da canção "A vingança", que a construção da narrativa, bem como o trabalho com a língua possuem características suficientes para atingirem o patamar das obras já consagradas pela crítica literária. Da mesma forma, estivemos respaldados, na análise do rap, na teoria usualmente aplicada aos textos canônicos com a finalidade de indicar que os mecanismos de produção do texto o localizam como uma das manifestações da literatura contemporânea, mais especificamente aquela que está deixando as margens e ocupando os centros.

\section{Referências bibliográficas}

Amado, J. (1937). Capitães da areia. José Olympio.

Barthes, R. (2000). Aula. Cultrix.

Benjamin, W. (1994). Magia e técnica, arte e política. Ensaios sobre literatura e história da cultura. Brasiliense. Bíblia (2008). Sagrada Bíblia Católica: Antigo e Novo Testamentos. Sociedade Bíblica de Aparecida.

Brasil (2020). Código Penal e Constituição Federal (1988). Saraiva.

Face da Morte (1998). A vingança. Vagalume. https://www.vagalume.com.br/face-da-morte/a-vinganca.ht $\underline{\mathrm{ml}}$

Face da Morte (2018). Entrevista com o grupo Face da Morte (parte 1). Submundo do som. http://www.sub mundodosom.com.br/2018/08/entrevista-com-o-grupo-face-da-morte.html

Face da Morte (2018). Entrevista com o grupo Face da Morte (parte 2). Submundo do som. http://www.sub mundodosom.com.br/2018/12/entrevista-face-da-morte-parte-ii.html

Fischer, L. A. (2014). 0 fim do cânone e nós com isso - passado e presente do ensino de literatura no Brasil. Remate de Males. 34(2), 573-611. https://doi.org/10.20396/remate.v34i2.8635866

Hollanda, H. B. (2018). Entrevista com Heloísa Buarque de Hollanda. Margens. https://margens.com.br/20 18/03/27/uma-marginal-na-academia-heloisa-buarque-de-hollanda

Malmaceda, A. L. B. (2017). A literatura nas canções dos Racionais MC'S: uma análise comparatista à luz de Rubem Fonseca, Paulo Lins e Ferréz [Dissertação de mestrado]. Universidade de Lisboa. https://repos itorio.ul.pt/handle/10451/30353

Melo Neto, J. C. (1955) Morte e vida severina. TUCA.

Miranda, W. S. (2011). Diálogos possíveis: do rap à literatura marginal. Darandina Revisteletrônica. 4(1), 1-18. https://www.ufjf.br/darandina/anteriores/v4n1/arr/

Oliveira, K. G. e Melo, C. T. V. (2014). Análise comparativa de músicas de protesto, a década de 1970 e o ano 2012. Intercom-XXXVII Congresso Brasileiro de Ciências da Comunicação, Brasil. https://www.portali ntercom.org.br/eventos1/congresso-nacional/2014

Pellegrini, T. (2005). As vozes da violência na cultura brasileira contemporânea. Crítica Marxista. 2(21), 132-153. https://www.ifch.unicamp.br/criticamarxista/sumario.php?id_revista=21\&numero_revista $\underline{=21}$ 
Ramos, G. (1953). Memórias do cárcere. José Olympio.

Salgado, M. R. (2015). Entre ritmo e poesia: rap e literatura oral urbana. Scripta. 19(37), 170-178. https:// doi.org/10.5752/P.2358-3428.2015v19n37p169

Žižek, S. (2014). Violência: seis reflexões laterais. Boitempo.

Cómo citar: Barros, A. M. de e Maldonado, R. S. (2021). A literatura das margens: análise da letra da canção "A vingança" como valorização do rap nos estudos literários contemporâneos. Boletín Galego de Literatura, 59, “Notas”, 1-12. DOI http://dx.doi.org/10.15304/bgl.59.8006 